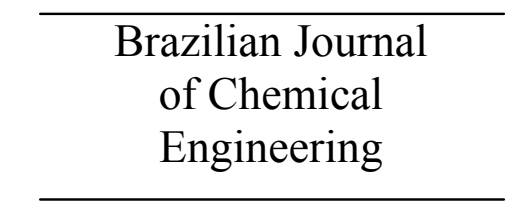

ISSN 0104-6632

Printed in Brazil

www.abeq.org.br/bjche

Vol. 29, No. 02, pp. 295 - 305, April - June, 2012

\title{
SYNTHESIS OF A BIOCOPOLYMER CARRAGEENAN- $g$-POLY(AAm-co-IA)/ MONTMORILONITE SUPERABSORBENT HYDROGEL COMPOSITE
}

\author{
M. Sadeghi \\ Department of Chemistry, Science Faculty, Islamic Azad University, \\ Phone: + 98-916-1613256, Fax: + 98-861-3670017, Arak Branch, Arak, Iran. \\ E-mail: m-sadeghi@iau-arak.ac.ir
}

(Submitted: June 13, 2011 ; Revised: September 26, 2011 ; Accepted: October 17, 2011)

\begin{abstract}
A novel superabsorbent hydrogel composite based on kappa-carrageenan $(\kappa \mathrm{C})$ has been prepared via graft copolymerization of acrylamide (AAm) and itaconic acid (IA) monomers in the presence of montmorolonite clay powder, methylenebisacrylamide (MBA) as the crosslinking agent and ammonium persulfate (APS) as initiator. Evidence of grafting and montmorolonite interaction was obtained by comparison of FTIR and TGA spectra of the initial substrates and the superabsorbent composite. A new absorption band at $1722 \mathrm{~cm}^{-1}$ in the composite spectrum confirmed montmorolonite-organic polymer linkages. Moreover, the morphology of the samples was examined by scanning electron microscopy (SEM). The swelling of the superabsorbing hydrogels was also examined in solutions with $\mathrm{pH}$ values ranging between 1.0 and 13.0. Finally, the swelling behavior of these composite polymers was investigated in various salt solutions. Results indicated that the swelling capacity decreased with an increase in the ionic strength of the swelling medium. This behavior can be attributed to the charge screening effect of monovalent cations, as well as ionic crosslinking for multivalent cations.
\end{abstract}

Keywords: Carrageenan; Acrylamide; Itaconic acid; Superabsorbent; Composite; Montmorolonite.

\section{INTRODUCTION}

Highly swelling polymers, i.e., superabsorbent hydrogels, are hydrophilic, three-dimensional networks that can absorb water in amounts from $10 \%$ up to thousands of times their dry weight (Osada and Khokhlov, 2005). They are widely used in various applications such as hygienic products, foods, cosmetics, and agriculture (Li et al, 2011; Buchholz and Graham, 1997; Hennink and Van Nostrum, 2002; Hoffman, 2002). This accounts for the increase in the worldwide production of superabsorbent polymers (SAPs) from 6000 tons in 1983 to 450000 tons in 1996 (Buchholz and Graham, 1997). Nowadays, the worldwide production of SAPs is more than one million tons in year. Hence, the synthesis and characterization of superabsorbent hydrogels is the main goal of several research groups in the world (Liu et al, 2011; Raghavendra et al, 2010; Mahkam and Allahverdipoor, 2004; Zhang et al, 2007; Chen et al, 2009; Sadeghi and Hosseinzadeh, 2008).

The properties of the swelling medium (e.g., pH, ionic strength and the counter ion and its valence) affect the swelling characteristics (Buchholz and Graham, 1997). Hydrogels that respond sharply and reproducibly to the medium conditions are referred to as "responsive", "smart" or "intelligent". Among these, $\mathrm{pH}$-sensitive hydrogels have been extensively investigated for their potential use in site-specific delivery of drugs to specific regions of the

*To whom correspondence should be addressed 
gastrointestinal tract and have been prepared for the delivery of low molecular weight protein drugs (Huixia et al, 2010; Zhou et al, 2011; Dai et al, 2007).

Although hydrogels made from synthetic polymers, such as polyacrylate, possess excellent water-absorbing properties, their toxicity and nonbiodegradability might pose long-time environmental problems and limit their use in drug delivery systems and consumer products. Natural-based SAPs polymers have attracted much attention in the medical and pharmaceutical fields because of their non-toxicity, biocompatibility and biodegradability. The higher production cost and low gel strength of these superabsorbents, however, restrict their wide application. To improve these limitations, inorganic compounds of low cost can be used. The introduction of inorganic fillers into a polymer matrix increases its strength and stiffness properties. Among inorganic compounds, special attention has been paid to clay minerals in the field of nanocomposites because of their small particle size and intercalation properties. Clay mineral powders are hydrated layered aluminosilicate with reactive $\mathrm{OH}$ groups on the surface. Interaction of mineral powders, the reactive site of natural polymers and monomers results in a superabsorbent composite. Superabsorbent composites based on synthetic polymers (Lin et al, 2001a; Lin et al, 2001b) or natural polymers (Bagheri Marandi et al, 2011; Wu et al, 2000; Wu et al, 2003) have been reported.

Carrageenan is a renewable and biodegradable natural polymer. For ages, carrageenan has been used in a variety of commercial applications due to its most practical property of gelatinization. Carrageenan is a viscosifying polysaccharide obtained commercially by extraction from certain species of red seaweeds. They are linear polysaccharides composed of $D$-galactose and 3,6anhydrogalactose units with varying degree of sulfonation. The sulfate groups make carrageenan a strongly anionic polymer (Kirk and Othmer, 1992).

In this work, we synthesize and characterize new superabsorbent composites based on carrageenan in the presence of montmorolonite particles. The presence of hydrophilic sulfate groups with high ionization tendency and reduced sensitivity to salt solutions was our main idea for the synthesis of carrageenan-based superabsorbent composites. The biopolymer-based superabsorbent composites can also improve the mechanical properties of materials and can lower the cost of the finished product compared with synthetic counterparts, as well as providing biodegradable characteristics. Finally, the swelling behavior in distilled water and various saline solutions and $\mathrm{pHs}$ was investigated as well.

\section{EXPERIMENTAL}

\section{Materials}

The polysaccharide kappa-carrageenan $(\kappa \mathrm{C}$, from Condinson Co., Denmark) was used without further purification. Itaconic acid (IA, Merck), acrylamide (from Merck) and ammonium persulfate (APS, Merck) were used without purification. MBA (from Fluka) and montmorolonite from Fluka, particle size $<5 \mu \mathrm{m}$ ) were used as received. All other chemicals were of analytical grade.

\section{Superabsorbent Composite Synthesis}

In a 1-liter reactor equipped with mechanical stirrer (Heidolph RZR 2021, three blade propeller type), variable amounts of $\kappa \mathrm{C}(0.2-1.5 \mathrm{~g})$ were added to $50 \mathrm{~mL}$ of degassed distilled water. The reactor was placed in a thermostated water bath to control the reaction temperature at $65^{\circ} \mathrm{C}$. After complete dissolution of $\mathrm{\kappa C}$, various amounts of montmorolonite powder $(0.25-0.75 \mathrm{~g})$ were added to the $\kappa \mathrm{C}$ solution and allowed to stir $(300 \mathrm{rpm})$ for $15 \mathrm{~min}$. After complete dissolution of the polysaccharide to form a homogeneous solution, a definite amount of APS solution (0.10-0.66 g in $5 \mathrm{~mL} \mathrm{H}_{2} \mathrm{O}$ ) was added to the mixture and allowed to stir for $15 \mathrm{~min}$. Then different amounts of AM (0.40$3.50 \mathrm{~g}$ in $\left.5 \mathrm{~mL} \mathrm{H}_{2} \mathrm{O}\right)$ and IA $(0.40-3.50 \mathrm{~g}$ in $5 \mathrm{~mL}$ $\left.\mathrm{H}_{2} \mathrm{O}\right)$ and MBA $\left(0.04-0.20 \mathrm{~g}\right.$ in $\left.5 \mathrm{~mL} \mathrm{H}_{2} \mathrm{O}\right)$ were simultaneously added to the reaction mixture. All of the reactions were carried out at 30 to $75^{\circ} \mathrm{C}$ under an argon atmosphere and the reaction mixture was continuously stirred $(300 \mathrm{rpm})$ for $1 \mathrm{~h}$. At the end of the propagation reaction, the superabsorbent hydrogel product was poured into ethanol $(300 \mathrm{~mL})$ and allowed to dewater for $24 \mathrm{~h}$. Then, the product was filtered and washed with $100 \mathrm{~mL}$ of ethanol. The filtered product was dried in an oven at $50^{\circ} \mathrm{C}$ for $10 \mathrm{~h}$. After grinding, the powdered superabsorbent composite was stored protected from moisture, heat and light.

\section{Swelling Measurements}

A small bag (i.e. a 100 mesh nylon screen) containing an accurately weighed powdered sample $(0.5 \pm 0.001 \mathrm{~g})$ with average particle sizes of 40-60 mesh $(250-350 \mu m)$ was entirely immersed in 
distilled water $(200 \mathrm{~mL})$ or the desired salt solution $(100 \mathrm{~mL})$ and allowed to soak for $3 \mathrm{~h}$ at room temperature. The bag was hung up for $15 \mathrm{~min}$ in order to remove the excess liquid. The maximum absorbency or equilibrated swelling (ES) was measured twice using the following equation:

$$
\mathrm{ES}(\mathrm{g} / \mathrm{g})=\frac{\begin{array}{c}
\text { Weight of swollen gel }- \\
\text { Weight of dried gel }
\end{array}}{\text { Weight of dried gel }}
$$

The accuracy of the measurements was $\pm 3 \%$.

\section{Absorbency at Various pHs}

Individual solutions with acidic and basic pHs were prepared by dilution of aqueous $\mathrm{NaOH}(\mathrm{pH}$ 13.0) and $\mathrm{HCl}(\mathrm{pH} 1.0)$ solutions to achieve $\mathrm{pH} \geq 6.0$ and $\mathrm{pH}<6.0$, respectively. The $\mathrm{pH}$ values were precisely checked with a $\mathrm{pH}$-meter (Metrohm/620, accuracy \pm 0.1$)$. Then, $0.5 \mathrm{~g}( \pm 0.001 \mathrm{~g})$ of the dried hydrogel was used for the swelling measurements according to Eq. (1).

\section{FTIR Analysis}

FTIR spectra of samples in the form of $\mathrm{KBr}$ pellets were recorded using an $\mathrm{ABB}$ Bomem MB100 FTIR spectrophotometer.

\section{RESULTS AND DISCUSSION}

\section{Synthesis and Characterization}

The superabsorbent composite was prepared by graft copolymerization of acrylamide and itaconic acid onto carrageenan in the presence of a crosslinking agent and powdered montmorolonite (Scheme 1). Ammonium persulfate was used as the initiator. The persulfate is decomposed under heating and produced sulfate anion-radicals that abstract hydrogen from $-\mathrm{OH}$ groups of the carrageenan backbone. This persulfatesaccharide redox system thus results in active centers capable of initiating radical polymerization of acrylic acid to give a graft copolymer. Since a crosslinking agent, MBA, is present in the system, the copolymer has a crosslinked structure.
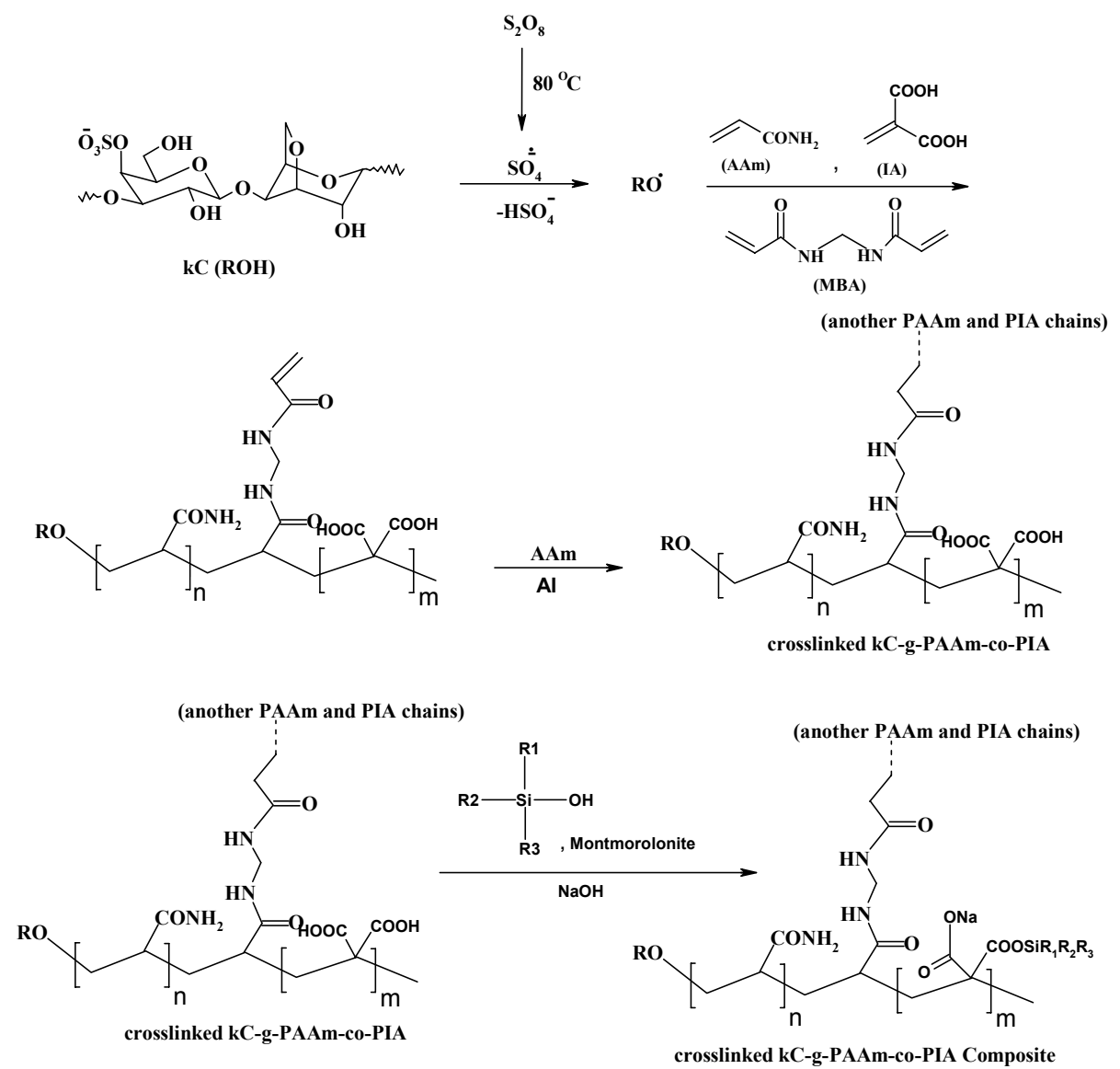

Scheme 1: Proposed mechanistic pathway for synthesis of the $\kappa \mathrm{C}$-based hydrogel composite. 
For identification of the product, FTIR spectroscopy was used. The FTIR spectra of the initial substrates and the composite graft copolymer are depicted in Figure 1. Fig. 1(a) represents the spectrum of montmorolonite. In the silicate layer structure, the hydroxyl groups show absorption bands at $3628-3675 \mathrm{~cm}^{-1}$. In Fig. 1(b), the bands observed at 836, 912, 1006, and $1228 \mathrm{~cm}^{-1}$ are attributed to D-galactose-4-sulfate, 3,6-anhydro-Dgalactose, the glycoside linkage and the sulfate ester stretch of $\kappa \mathrm{C}$, respectively. The broad band at $3200-$ $3400 \mathrm{~cm}^{-1}$ is due to stretching of $-\mathrm{OH}$ groups of the polysaccharide. In the spectrum of the composite (Fig. 1(d)), two new absorption peaks at 1572 and $1722 \mathrm{~cm}^{-1}$ appear. The characteristic band at $1572 \mathrm{~cm}^{-1}$ is due to the $\mathrm{C}=\mathrm{O}$ asymmetric stretch of the carboxylate anion that is reconfirmed by another peak at $1410 \mathrm{~cm}^{-1}$ which is related to the symmetric stretching mode of the carboxylate groups. The absorption band at $1722 \mathrm{~cm}^{-1}$ can be attributed to ester groups formed during the graft polymerization reaction. The carboxylate groups of the grafted poly(itaconic acid) can be react with the - $\mathrm{OH}$ groups on the montmorolonite surface. The replacement of hydroxyl groups on the surface of montmorolonite by carboxylate anions results in the ester formation.

Figure 1(c) shows the spectrum of the $\mathrm{H}-\kappa \mathrm{C}-\mathrm{g}$ AAm-co-IA without the montmorolonite powder. As shown in this figure, absorption bands appear at 2630$3674 \mathrm{~cm}^{-1}$ that reflect the incorporation of hydrogen bonding $\left(-\mathrm{OH}\right.$ or $\left.-\mathrm{NH}_{2}\right)$ groups of itaconic acid and acrylamide in the graft copolymerization reaction.

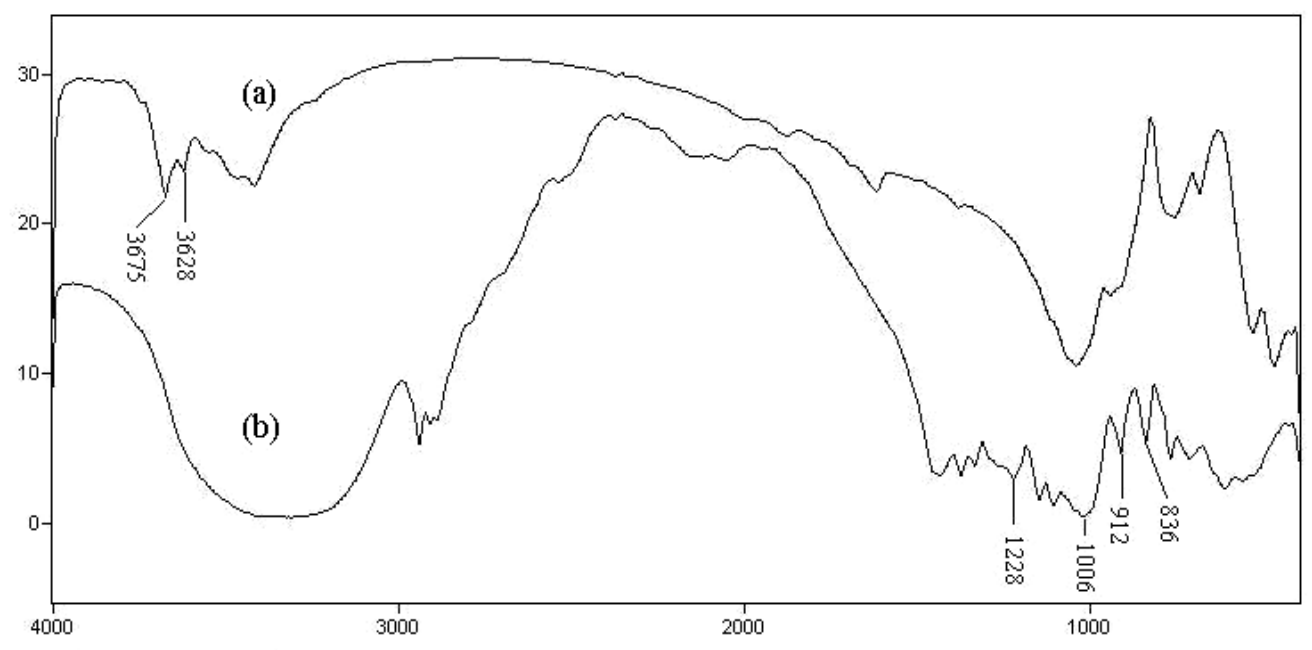

Transmittance/Wavenumber( $\mathrm{cm}-1)$

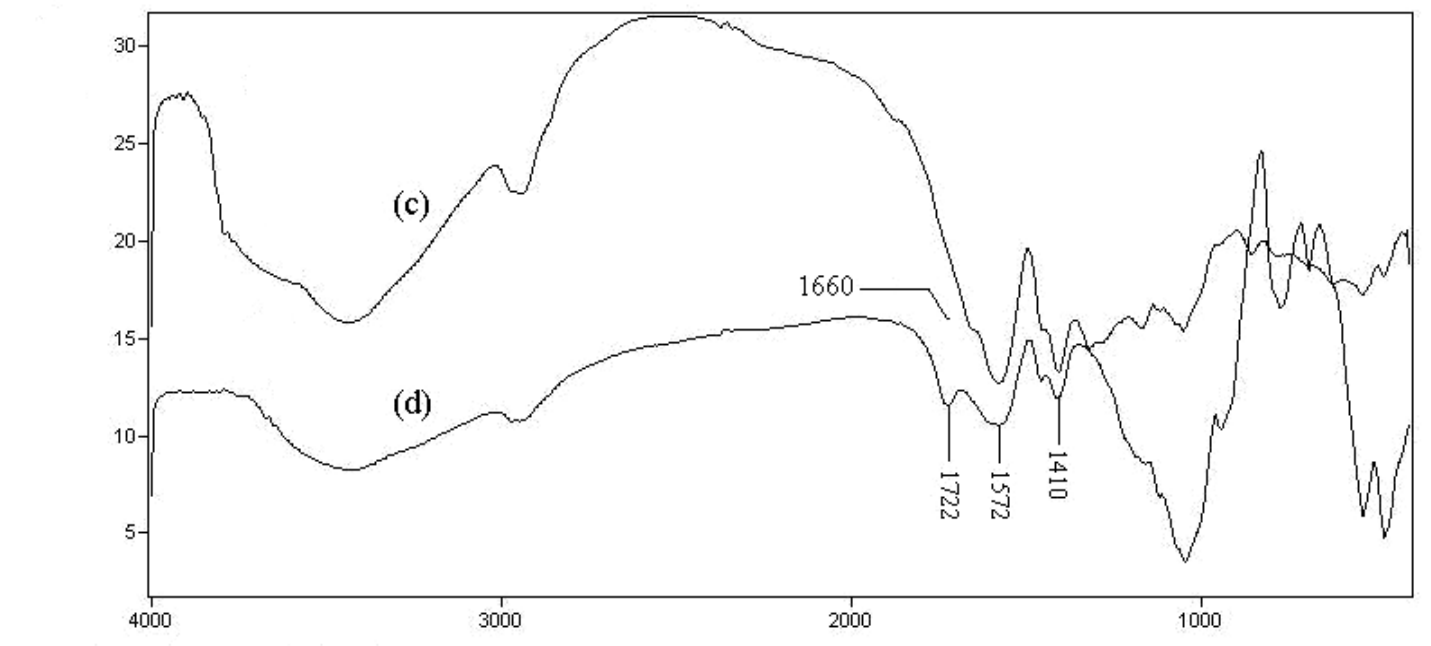

Transmittance/Wavenumber(cm-1)

Figure 1: FTIR spectra of: (a) montmorolonite; (b) $\kappa \mathrm{C}$; (c) $\mathrm{H}-\kappa \mathrm{C}-\mathrm{g}-\mathrm{PAAm}-\mathrm{co}-\mathrm{PIA}$ hydrogel; and

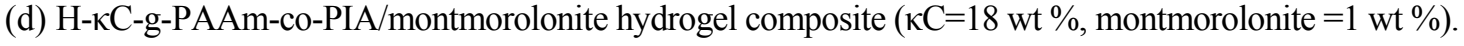




\section{Scanning Electron Microscopy}

One of the most important properties that must be considered is the hydrogel microstructure morphology. The surface morphology of the samples was investigated by scanning electron microscopy. Figure 2 shows SEM micrographs of the kappa-

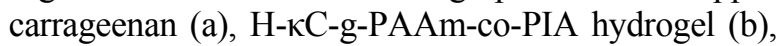
and $\mathrm{H}-\kappa \mathrm{C}-\mathrm{g}$-PAAm-co-PIA/montmorolonite composite hydrogel (c) surfaces obtained from the fracture surface. The hydrogels have a porous structure. It is assumed that these pores are the regions of water permeation and the interaction sites of external stimuli with the hydrophilic groups of the graft copolymers. Because of the crosslinking role of montmorolonite, the hydrogel composites have a structure with more pores, but smaller in size, in comparison with the hydrogel without any clay.
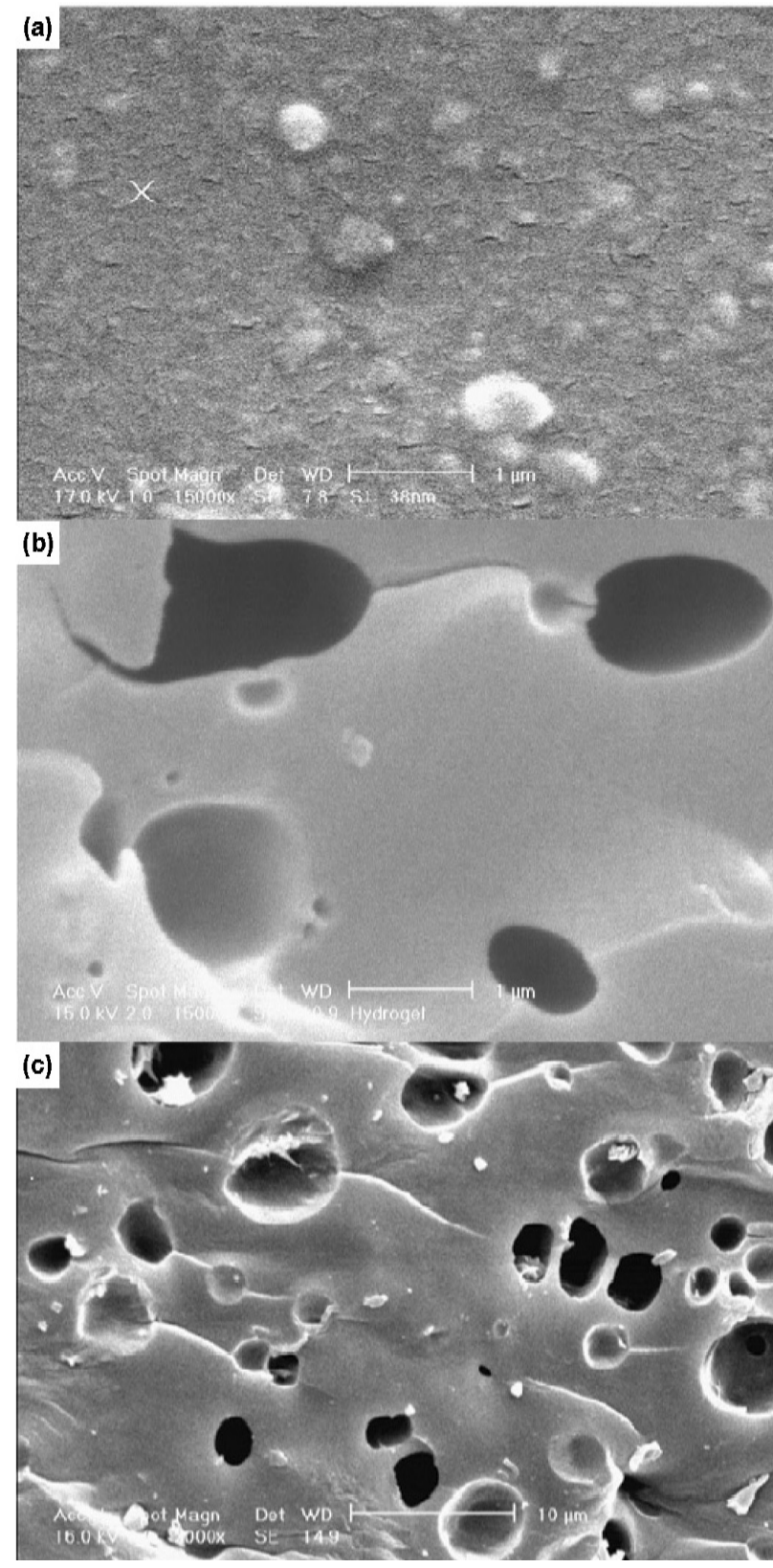

Figure 2: SEM photographs of kappa-carrageenan

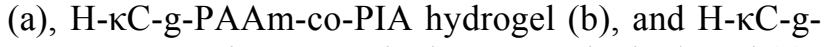
PAAm-co-PIA/montmorolonite composite hydrogel (c). 


\section{Thermal Analysis}

Thermogravimetric analysis (TGA) was employed to characterize the composite hydrogel thermally in comparison with raw kappa-carrageenan (Figure 3).

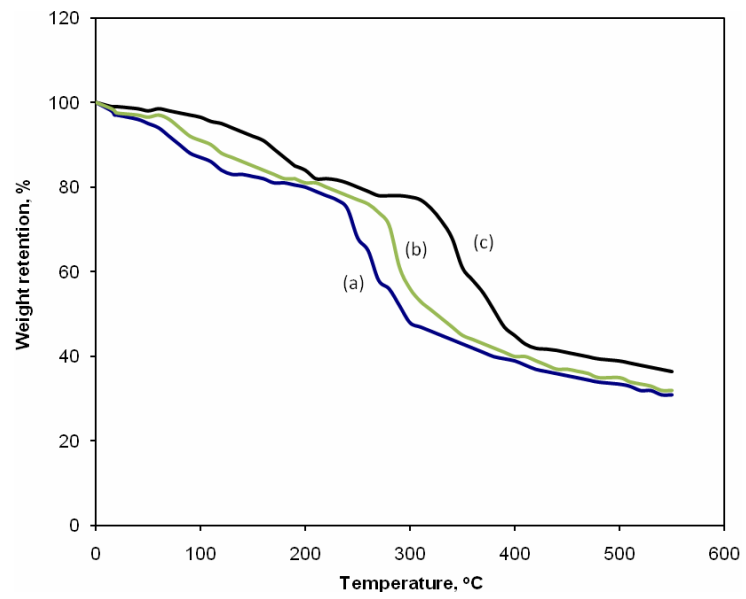

Figure 3: TGA of kappa-carrageenan (a), H- $\mathrm{CC}-\mathrm{g}-$ PAAm-co-PIA hydrogel (b), and H- $\kappa \mathrm{C}-\mathrm{g}$-PAAm-co$\mathrm{PIA} /$ montmorolonite composite hydrogel (c).

The thermal stability of the grafted carrageenan is improved, as is obvious from the TGA curve. The TGA of carrageenan (Figure 3(a)) shows a weight loss in two distinct stages. The first stage between 10 and $130^{\circ} \mathrm{C}$ shows about $17 \%$ loss in weight. This may correspond to the loss of adsorbed and bound water. No such inflection was observed in the TGA curve of the H- $\mathrm{KC}$-g-PAAm-co-PIA/montmorolonite composite hydrogel (Figure 3(c)). This indicated that the grafted copolymers were resistant to moisture absorption. The second stage of weight loss starts at $230^{\circ} \mathrm{C}$ and continues up to $300^{\circ} \mathrm{C}$, during which there was a $52 \%$ weight loss due to the degradation of carrageenan. In general, the degradation of native carrageenan is faster than that of grafted carrageenan. About $60 \%$ weight loss takes place in the temperature range of $220-370^{\circ} \mathrm{C}$ for carrageenan.

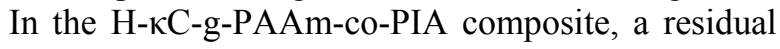
weight of $77 \%$ was observed at $310^{\circ} \mathrm{C}$. The appearance of these stages indicates that the structure of carrageenan backbones has been changed, which might be due to the grafting of poly(AAm-co-IA)/ montmorolonite chains. In general, the copolymer had a lower weight loss than carrageenan. This means that the grafting of carrageenan increases the thermal stability of carrageenan to some extent. We also studied the thermal stability of hydrogels in the presence and absence of montmorolonite. As observed from comparison of Figures 3(b) and 3(c), incorporation of clay into the hydrogel structure increases the thermal stability of the composites. This is attributed to the fact that the montmorolonite particles act as a crosslinking agent and improve the structural stability of the hydrogel network.

\section{Optimization of the Grafting Conditions}

In this work, optimization of the grafting conditions (i.e., concentration of $\kappa \mathrm{C}$, MBA, AAm, IA, clay and APS and reaction bath temperature), as well as the swelling behavior of the resulting pH-responsive superabsorbent hydrogels were investigated. It should be pointed out that, in the case of optimization of the grafting conditions for systems with and without clay, incorporation of montmorolonite increases the gel mechanical strength and decreases the swelling capacity of the resulting hydrogel composites due to the crosslinking property of clay. However, because clay had no remarkable effect on the optimization of grafting, we also optimized the reaction conditions for hydrogels without any clay (Figures 4-8).

\section{Effect of MBA Concentration on Swelling}

Crosslinks are necessary to form a superabsorbent in order to prevent dissolution of the hydrophilic polymer chains in an aqueous environment. The effect of MBA concentration on the water absorbency of the hydrogel and composite was studied by varying the concentration of MBA from 0.004 to $0.03 \mathrm{~mol} / \mathrm{L}$. All other parameters in these series of reactions were maintained constant. As the concentration of MBA was increased, the water absorbency of the superabsorbent composite decreased. This known behavior is shown in Figure 4. This is due to a decrease in the space between the copolymer chains as the crosslinker concentration is increased. This decreasing trend is similar to that found by us (Sadeghi and Hosseinzadeh, 2010) and other groups (Chen and Zhao, 2000) for other superabsorbents.

\section{Effect of Monomer Ratio on Swelling Capacity}

The swelling capacity of the hydrogel and composites prepared with various ratios of monomers is shown in Fig. 5. Since the $\mathrm{pH}$ of the polymerization mixture was adjusted to 8.0 after the reaction, the superabsorbency of $\mathrm{H}-\mathrm{\kappa C}-\mathrm{g}-(\mathrm{PNaIA}-$ PAAm) hydrogel is due to both ionic carboxylate (from neutralized IA) and ionic carboxamide (from 
AAm) functional groups. The presence of the ionic groups in the polymer chains results in an increase of swelling because the ionized groups are more strongly solvated than non-ionic or non-ionized groups in the aqueous medium. Higher swelling capacities are obtained by employing higher initial ratios of NaIA/AAm. Therefore, the swelling enhancement at higher NaIA/AAm ratios can be attributed to the formation of more carboxylate groups in the synthesized samples.

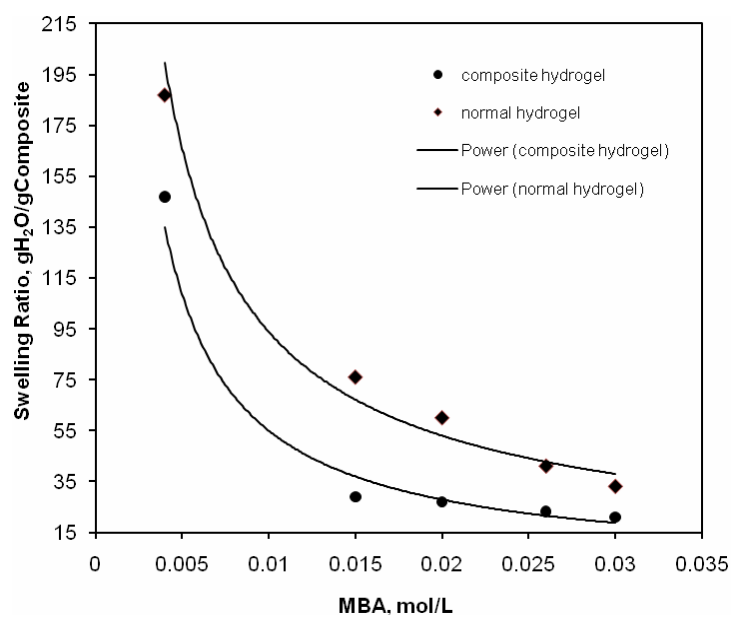

Figure 4: Effect of the crosslinker concentration on water absorbency of the normal and composite hydrogel (Reaction conditions: $\kappa \mathrm{C}=$ montmorolonite $=0.01 \mathrm{wt} \%$, AAm $0.5 \mathrm{~mol} / \mathrm{L}$, IA $1.2 \mathrm{~mol} / \mathrm{L}$, APS $0.017 \mathrm{~mol} / \mathrm{L}$, $\left.70^{\circ} \mathrm{C}, 1 \mathrm{~h}\right)$.

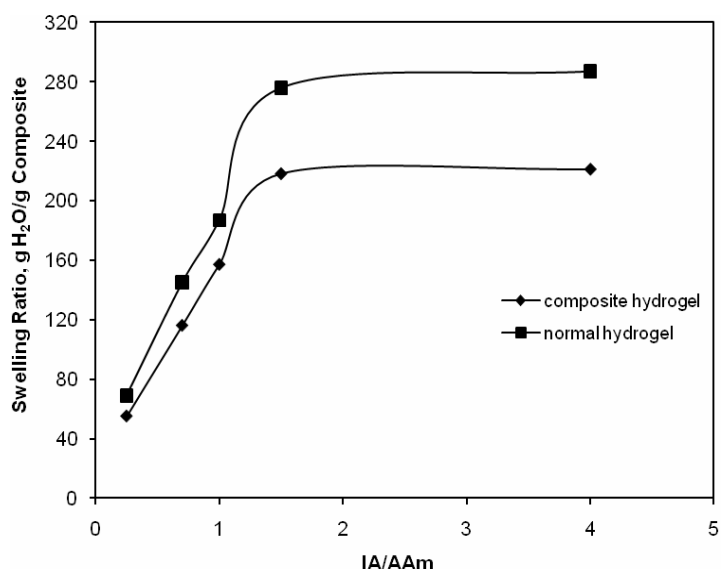

Figure 5: Water absorbency dependency of the normal and composite hydrogel on the monomer ratio (Reaction conditions: $\kappa \mathrm{C}=$ montmorolonite $=0.01 \mathrm{wt} \%$, MBA $0.004 \mathrm{~mol} / \mathrm{L}$, APS $0.017 \mathrm{~mol} / \mathrm{L}, 70^{\circ} \mathrm{C}, 1 \mathrm{~h}$ ).

\section{Effect of APS Concentration on Swelling}

The effect of the initiator concentration on the water absorbency of the superabsorbents was also studied (Fig. 6). The APS concentration was changed from 0.005 to $0.039 \mathrm{~mol} / \mathrm{L}$. Water absorbency of the composite increased initially with increasing initiator concentration up to $0.011 \mathrm{~mol} / \mathrm{L}$, but then decreased, as shown in Fig 6. The increase of water absorbency with increasing initiator concentration can be ascribed to the increase in the active sites on the backbone of the $\kappa \mathrm{C}$ arising from the attack of the sulfate anion-radical. An additional reason, according to Flory, is the imperfection of the polymer networks obtained from high-initiator polymerization systems.

The increase in the active sites on the polysaccharide led to an increase of NaIA and AAm grafting onto the $\kappa \mathrm{C}$ backbone. The decrease of water absorbency with initiator concentration beyond $0.011 \mathrm{~mol} / \mathrm{L}$ may be due to: (a) the increased number of produced radicals favoring the terminating step via bimolecular collision; (b) the predominance of homopolymerization over grafting; (c) molecular weight loss of the synthetic part of the polymer network (Flory 1953); and (d) free radical degradation of the $\kappa \mathrm{C}$ substrate. Hsu et al. (2002) have reported a similar observation in the case of degradation of chitosan with potassium persulfate.

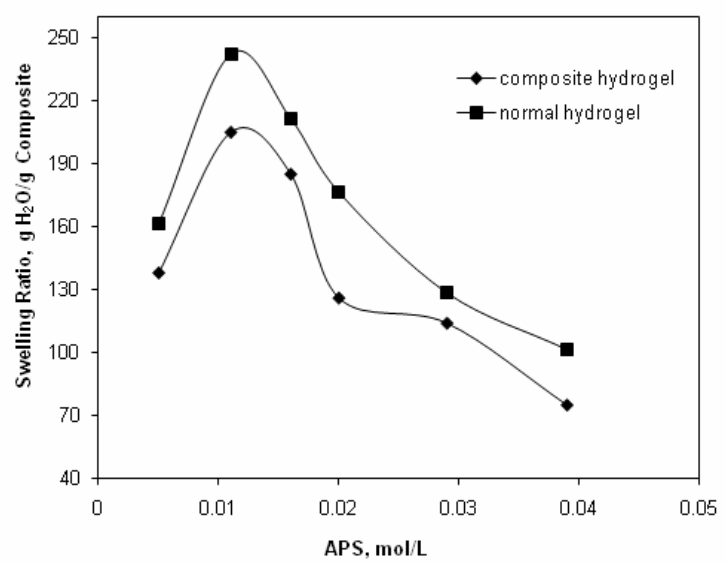

Figure 6: Effect of initiator concentration on water absorbency of the normal and composite hydrogel (Reaction conditions: $\kappa \mathrm{C}=$ montmorolonite $=0.01 \mathrm{wt} \%$, MBA $0.004 \mathrm{~mol} / \mathrm{L}$, AAm $0.4 \mathrm{~mol} / \mathrm{L}$, IA $1.6 \mathrm{~mol} / \mathrm{L}$, $\left.70^{\circ} \mathrm{C}, 1 \mathrm{~h}\right)$.

\section{Effect of Montmorolonite/кC Ratio on Swelling}

The effect of montmorolonite content on the water absorbency of the hydrogels was also studied (Figure 7). The montmorolonite $/ \kappa \mathrm{C}$ weight ratio was varied from 0 to 2.50 , while other reaction variables were maintained constant. The effect of montmorolonite amount on water absorbency is 
similar to the influence of MBA on absorbency. Figure 7 indicates that the water absorbency of the superabsorbent is decreased with increasing montmorolonite amount incorporated in the composite structure. The clay in the polymerization reaction may act in two ways: (a) montmorolonite particles act as a crosslinking agent (i.e., the carboxylate groups of sodium poly(itaconic acid) chains react with montmorolonite) and (b) montmorolonite particles prevent the growth of the polymer chains through a chain transfer mechanism (Lin et al, 2001b). Again, we observed that the swelling capacities of normal hydrogels are higher than those of composite hydrogels.

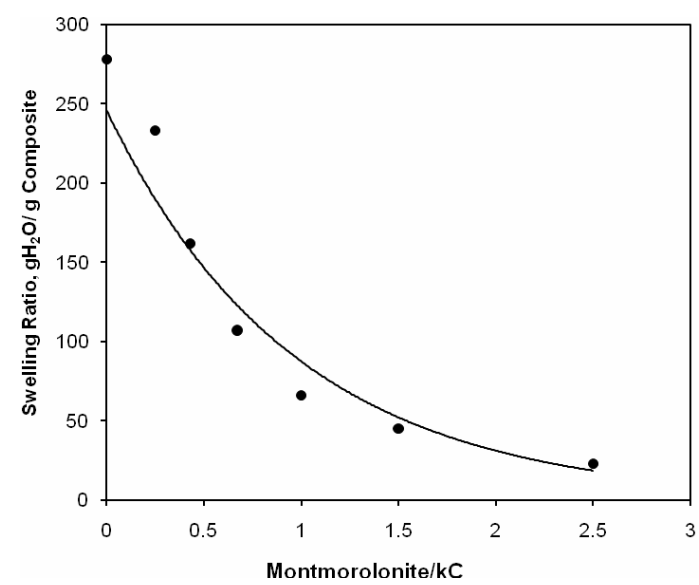

Figure 7: Effect of montmorolonite $/ \mathrm{\kappa C}$ weight ratio on water absorbency of the hydrogels (Reaction conditions: MBA $0.004 \mathrm{~mol} / \mathrm{L}$, AAm $0.4 \mathrm{~mol} / \mathrm{L}$, IA $1.6 \mathrm{~mol} / \mathrm{L}$, APS $0.011 \mathrm{~mol} / \mathrm{L}, 70^{\circ} \mathrm{C}, 1 \mathrm{~h}$ ).

\section{Effect of Bath Temperature on Swelling Capacity}

To study the influence of reaction temperature on water absorbency, the graft copolymerization of IA and AAm onto carrageenan was carried out at six temperatures ranging from 30 to $75^{\circ} \mathrm{C}$ and the results are presented in Figure 8 . The swelling capacity of the hydrogels increased with increasing the temperature from 30 to $65^{\circ} \mathrm{C}$, and then decreased. At $65^{\circ} \mathrm{C}$, maximum swelling (235 g/g) was obtained. The increase in water absorbency up to $65^{\circ} \mathrm{C}$ could be attributed to the following factors during the grafting reaction as increased number of free radicals formed on the carrageenan backbone, increased propagation of the graft copolymerization onto carrageenan, enhanced diffusion of monomers and initiator into and onto the backbone structure, and increased mobility of the monomers and a higher collision probability with the backbone macroradicals. However, the swelling capacity decreased as the bath temperature was raised beyond $65^{\circ} \mathrm{C}$. This can be accounted for in terms of radical chain termination at higher temperatures (Lim, et al., 2001).

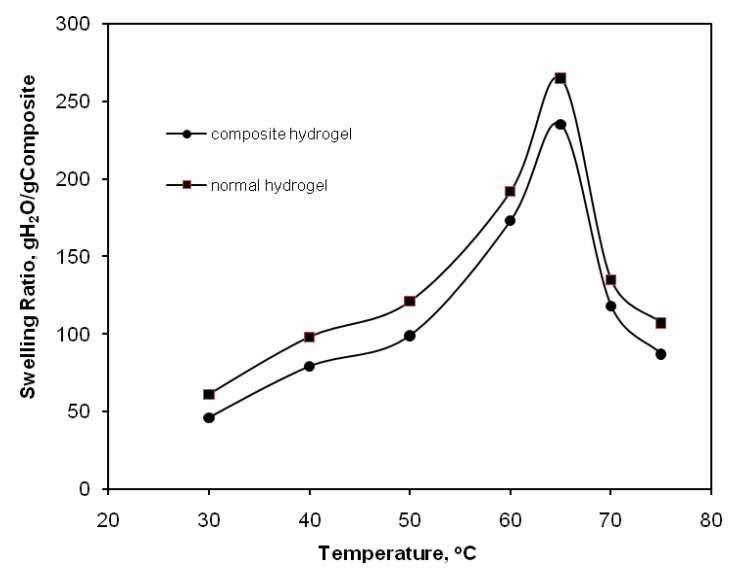

Figure 8: Effect of reaction temperature on swelling capacity of the normal and composite hydrogel (Reaction conditions: $\kappa \mathrm{C}=$ montmorolonite $=0.01 \mathrm{wt} \%$, MBA $0.004 \mathrm{~mol} / \mathrm{L}$, AAm $0.4 \mathrm{~mol} / \mathrm{L}$, IA $1.6 \mathrm{~mol} / \mathrm{L}$, APS $0.011 \mathrm{~mol} / \mathrm{L}, 1 \mathrm{~h})$.

\section{Effect of pH on Equilibrium Swelling}

Figure 9 represents the $\mathrm{pH}$ dependence of the equilibrium swelling for $\mathrm{H}-\kappa \mathrm{Cg}-\mathrm{PAAm}-\mathrm{co}-\mathrm{PNaIA}$ hydrogel composites at ambient temperature $\left(25^{\circ} \mathrm{C}\right)$. The equilibrium swelling of the hydrogels was studied at various pHs ranging from 1.0 to 13.0. No additional ions (e.g., from buffer solution) were added to the medium to control the $\mathrm{pH}$ ranging of a superabsorbent is strongly affected by the ionic strength. In addition, it has been reported that the swelling properties of polybasic gels are influenced by buffer composition (composition and $\mathrm{pK}_{\mathrm{a}}$ ). Therefore, $\mathrm{NaOH}(\mathrm{pH} 13.0)$ and $\mathrm{HCl}(\mathrm{pH} 1.0)$ stock solutions were diluted with distilled water to reach the desired basic and acidic $\mathrm{pHs}$, respectively.

The effective $\mathrm{pKa}$ for kappa-carrageenan is 4.9 and that for carboxylic acid groups is $~ 4.6$. In Figure 9, the dependence of the equilibrium swelling of the $\mathrm{H}-$ $\kappa \mathrm{Cg}$-PAAm-co-PNaIA hydrogel composite is characterized by a curve with two maxima at $\mathrm{pHs} 3$ and 8 . The remarkable swelling changes are due to the presence of different interacting species depending on $\mathrm{pH}$ of the swelling medium. It can be assumed that the $\mathrm{H}-\kappa \mathrm{Cg}-\mathrm{PAAm}-\mathrm{co}-\mathrm{PNaIA}$ hydrogel includes kappa-carrageenan, poly(itaconic acid) and poly(acrylamide) structures. The structures of kappacarrageenan and PIA are ionizable. Therefore, based 
upon the $\mathrm{pK}_{\mathrm{a}}$ of PIA ( 4.6) and the $\mathrm{pK}_{\mathrm{a}}$ of carrageenan (4.9), the species involved are $\mathrm{NH}_{3}{ }^{+}$and $\mathrm{COOH}$ (at pHs 1-3), $\mathrm{NH}_{2}$ and $\mathrm{COO}^{-}$(at $\mathrm{pHs} 7-13$ ) and $\mathrm{NH}_{3}{ }^{+}$and $\mathrm{COO}^{-}$or $\mathrm{NH}_{2}$ and $\mathrm{COOH}$ (at $\mathrm{pHs} 4-7$ ). Under acidic conditions, the swelling is controlled mainly by $\mathrm{NH}_{2}$ groups on the acrylamide component. It is a weak base with an intrinsic $\mathrm{pK}_{\mathrm{a}}$ of about 4.9, so it is protonated and the increased charge density on the polymer should enhance the osmotic pressure inside the gel particles because of the $\mathrm{NH}_{3}{ }^{+}-\mathrm{NH}_{3}{ }^{+}$ electrostatic repulsion. This osmotic pressure difference between the internal and external solution of the network is balanced by the swelling of the gel. However, under a very acidic condition $(\mathrm{pH}<3)$, a screening effect of the counter ion, i.e., $\mathrm{Cl}^{-}$, shields the charge of the ammonium cations and prevents an efficient repulsion. As a result, a remarkable decrease in equilibrium swelling is observed (gel collapse). At $\mathrm{pH}>4.7$, the carboxylic acid component comes into action as well. Since the $\mathrm{pK}_{\mathrm{a}}$ of the weak poly acid is about $\sim 4.7$, its ionization above this $\mathrm{pH}$ value may favor enhanced absorbency. But below $\mathrm{pH} 6.4$, or in the $\mathrm{pH}$ range $4-7$, the majority of the basic and acidic groups are present as $\mathrm{NH}_{3}{ }^{+}$and $\mathrm{COO}^{-}$or $\mathrm{NH}_{2}$ and $\mathrm{COOH}$. Ionic interaction of $\mathrm{NH}_{3}{ }^{+}$ and $\mathrm{COO}^{-}$species (ionic crosslinking) or hydrogen bonding between amine and carboxylic acid (and probably carboxamide) groups can therefore lead to a kind of crosslinking followed by decreased swelling. At $\mathrm{pH}$ 8, the carboxylic acid groups become ionized and the electrostatic repulsive force between the charged sites $\left(\mathrm{COO}^{-}\right)$cause an increase in swelling. Again, a screening effect of the counter ions $\left(\mathrm{Na}^{+}\right)$limits the swelling at $\mathrm{pHs} 9-13$.

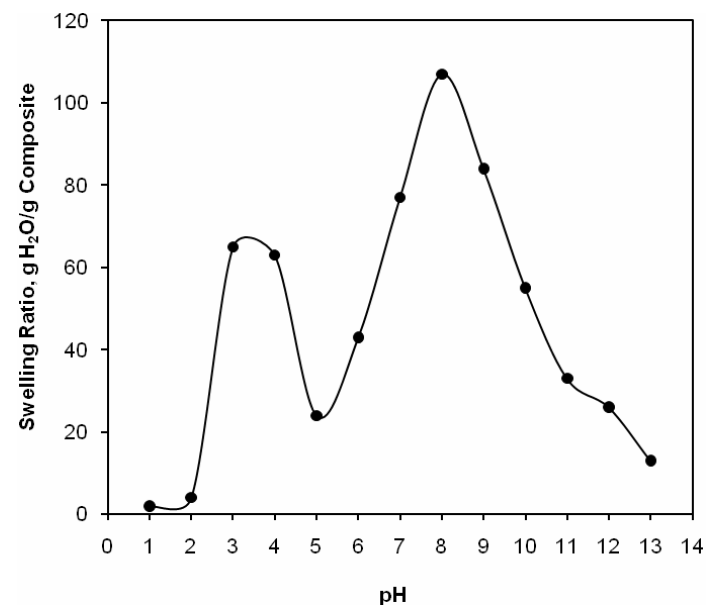

Figure 9: $\mathrm{pH}$-dependent swelling of the superabsorbent composite (containing $12 \mathrm{wt} \% \mathrm{\kappa C}$ and $3 \mathrm{wt} \%$ montmorolonite).

\section{Swelling Behavior in Salt Solutions}

Changing the ionic strength significantly affects the swelling capacity of superabsorbents. Figure 10 shows the effect of various salt solutions of different concentrations on the water absorbency of the $\kappa \mathrm{C}$-g-PAAm-co-IA/montmorolonite composite. The decrease of the swelling capacity of the hydrogels is due to the screening effect and a loss of the osmotic pressure difference between the hydrogels and the fluids. The superabsorbents have carboxylate groups in their structures. In salt solutions, the anion-anion repulsion of the carboxylate groups is prevented by the $\mathrm{M}^{\mathrm{n}+}$ cations that shield the carboxylate groups, so the swelling capacity is decreased. In addition, the swelling of the superabsorbents depends on the valency of the cations. Multivalent cations drastically decrease the swelling capacity. The decrease is attributed to the complexing ability of carboxylate groups, inducing interchain complex formation and consequent enhancement of the network crosslink density. The water absorbency of the composite in the presence of $\mathrm{Ca}^{2+}$ and $\mathrm{Al}^{3+}$ cations is lower than that in $\mathrm{NaCl}$ solution. This phenomenon reflects the ionic crosslinking of these multivalent cations with carboxylate anions, which causes low water absorbency. As a result, the swelling of the composite, especially in salt solutions, is higher than that of its non-composite counterpart. The swelling improvement may be attributed to attraction of the salt cations on the surface of montmorolonite in the composite hydrogel, which results in a lower screening effect in the composite compared with the similar montmorolonite-free sample. The reason for this anti-salt behavior can be explained as follows: the $\kappa \mathrm{C}$-containing networks comprise both sulfate and carboxylate functional groups. The sulfate groups can be dissociated in aqueous media more readily than the carboxylate groups of the synthetic part of the composite hydrogels (in this regard, the pKa of methane sulfonic acid, -2.0, may be compared with that of acetic acid, 4.8). Therefore, the sulfate ions do not keep cations in their vicinity, so the charge screening effect is not very effective. Similar conclusions were recently reported by Lim et al. (2001) in the case of sodium starch sulfate-gpolyacrylonitrile superabsorbent and Barbucci et al. (2000) in the case of a sulfated carboxymethylcellulose hydrogel. They attributed the enhanced absorbency in saline solutions to increased charge density and ionization tendency brought about by the introduction of sulfate anions. 

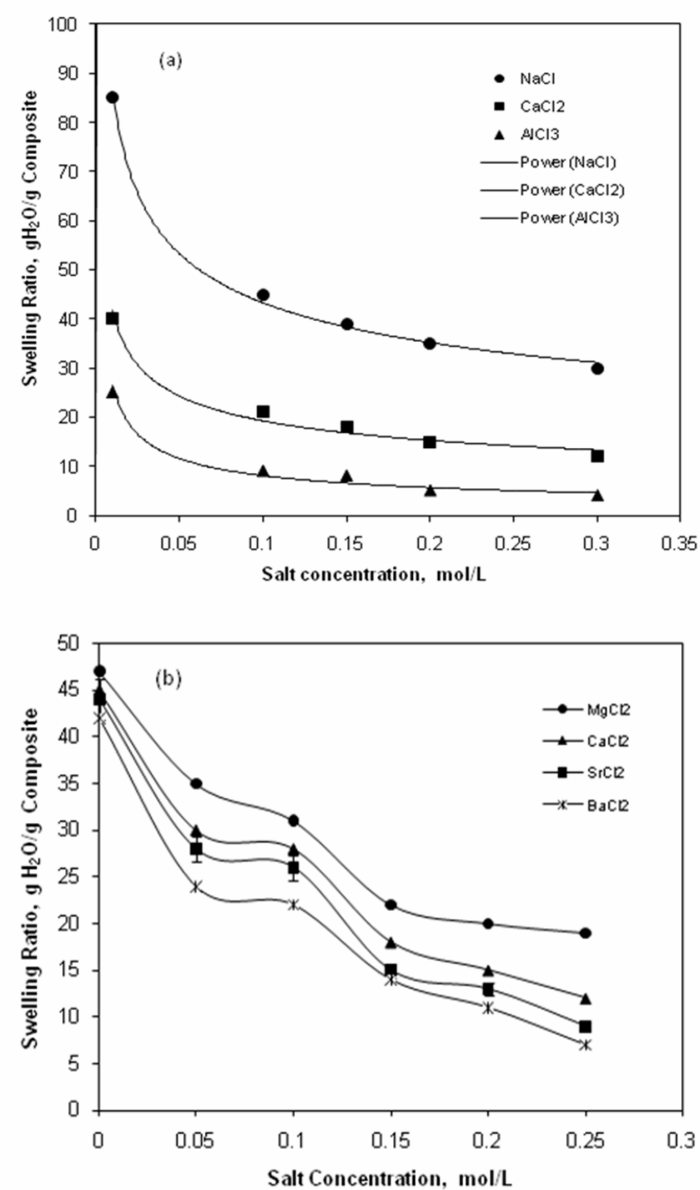

Figure 10: Swelling capacity variation of superabsorbent composite (containing $12 \mathrm{wt} \% \mathrm{\kappa C}$ and $3 \mathrm{wt} \%$ montmorolonite) in different saline solutions with various concentrations of multivalent cations (a) and divalent cations (b).

\section{CONCLUSION}

A novel superabsorbent composite was prepared by graft copolymerization of AAm and IA onto kappa-carrageenan in the presence of a crosslinking agent. The resultant superabsorbent composite had a large degree of water absorbency. The FTIR spectra show a new absorption band at $1722 \mathrm{~cm}^{-1}$ in the composite spectrum attributed to ester formation from replacement of hydroxyl groups of montmorolonite with carboxylate anions grafted onto polysaccharide backbones. The effect of the amount of clay and MBA concentration showed that increasing these parameters decreased the water absorbency of the superabsorbent composite. The swelling of hydrogels in solutions with various $\mathrm{pHs}$ exhibited a high sensitivity to $\mathrm{pH}$. Swelling measurements of the synthesized composites in different salt solutions showed appreciable swelling capacity, especially in $\mathrm{NaCl}$ solution, due to an antisalt characteristic originated mainly from the carrageenan sulfate groups of the superabsorbing network. Overall, we report a crosslinking polymerization to achieve superabsorbing composite materials with lower cost and lower salt-sensitivity. The hydrogel composites will most probably possess higher biodegradability (due to the $\kappa \mathrm{C}$ part) and higher swollen gel strength (due to the inorganic parts). The latter properties are currently under consideration in our laboratory.

\section{REFERENCES}

Bagheri Marandi, G., Mahdavinia, G. R. and Ghafary, Sh., Swelling behavior of novel proteinbased superabsorbent nanocomposite. J. Appl. Polym. Sci., 120, 1170 (2011).

Barbucci, R., Maganani, A. and Consumi, M., Swelling behavior of carboxymethylcellulose hydrogels in relation to cross-linking, $\mathrm{pH}$, and charge density. Macromolecules, 33, 7475 (2000).

Buchholz, F. L. and Graham, A. T., Modern Superabsorbent Polymer Technology. Wiley, New York (1997).

Chen, Y., Liu, Y. F., Tan, H. M. and Jiang, J. X., Synthesis and characterization of a novel superabsorbent polymer of N,O-carboxymethyl chitosan graft copolymerized with vinyl monomers. Carbohyd. Polym., 75, 287 (2009).

Chen, J. and Zhao, Y., Relationship between water absorbency and reaction conditions in aqueous solution polymerization of polyacrylate superabsorbents. J. Appl. Polym. Sci., 75, 808 (2000).

Dai, Y., Li, P. and Wang, A., Intelligent drug delivery system of intelligent high polymer materials. Prog. Chem., 19, 362 (2007).

Flory, P. J., Principles of Polymer Chemistry. Ithaca, Cornell University Press, New York, (1953).

Hennink, W. E. and van Nostrum, C. F., Novel crosslinking methods to design hydrogels. Adv. Drug Deliv. Rev., 54, 13 (2002).

Hoffman, A. S., Hydrogel for biomedical applications. Adv. Drug. Deliver. Rev., 43, 3 (2002).

Hsu, S. C., Don T. M. and Chiu, W. Y., Free radical degradation of chitosan with potassium persulfate. Polym. Degrad. Stab., 75, 73 (2002).

Huixia, S. H. Wang, W. and Wang, A., Controlled release of ofloxacin from chitosan-montmorillonite hydrogel. Appl. Clay Sci., 50, 112 (2010). 
Kirk, R. E. and Othmer, D. F., Encyclopedia of Chemical Technology. Vol. 4, Kroschwitz, J. I., Howe-Grant, M., (Eds.), John Wiley \& Sons, New York, p. 942 (1992).

Li, H., Yang, J., Hu, X., Liang, J., Fan, Y. and Zhang, X., Superabsorbent polysaccharide hydrogels based on pullulan derivate as antibacterial release wound dressing. J. Biomed. Mater. Res., A., 98, 31 (2011).

Lim, D. W., Whang, H. S. and Yoon, K. J., Synthesis and absorbency of a superabsorbent from sodium starch sulfate-g-polyacrylonitrile. J. Appl. Polym. Sci., 79, 1423 (2001).

Lin, J., Wu, J., Yang, Z. and Pu, M., Synthesis and properties of poly(acrylic acid)/mica superabsorbent nanocomposite. Macromol. Rapid Commun., 22, 422 (2001a).

Lin, J., Wu, J., Yang, Z. and Pu, M., Synthesis and properties of poly(acrylic acid)/montmorillonite superabsorbent composites. Polym. Polym. Compos., 9, 469 (2001b).

Liu, X., Li, X., Lu, Z., Miao, X. and Feng, Y., Modified acrylic-based superabsorbents with hydrophobic monomers: synthesis, characterization and swelling behaviors. J. Polym. Res., 18, 897 (2011).

Mahkam, M. and Allahverdipoor, M., Controlled release of biomolecules from $\mathrm{pH}$-sensitive network polymers prepared by radiation polymerization. J. Drug Target, 12, 151 (2004).

Osada, Y. and Khokhlov, R., Polymer Gels and Networks. Marcel Dekker, Inc. New York (2005).
Raghavendra, V., Kulkarni, V., Mutalik, S., Setty, $\mathrm{M}$. and $\mathrm{Sa}, \mathrm{B}$., Interpenetrating network hydrogel membranes of sodium alginate and poly(vinyl alcohol) for controlled release of prazosin hydrochloride through skin. Int. J. Biol. Macromol., 47, 520 (2010).

Sadeghi, M. and Hosseinzadeh, H., Synthesis and super-swelling behavior of a novel low saltsensitive protein-based superabsorbent hydrogel: collagen-g-poly(AMPS). Turk. J. Chem., 34, 739 (2010).

Sadeghi, M. and Hosseinzadeh, H., Synthesis of starch-poly(sodium acrylate-co-acrylamide) superabsorbent hydrogel with salt and $\mathrm{pH}$ responsiveness properties. Turk. J. Chem., 32, 375 (2008).

Wu, J., Lin, J., Zhou, M. and Wei, C., Synthesis and properties of starch-g-polyacrylamide/clay superabsorbent composite. Macromol. Rapid Commun., 21, 1032 (2000).

Wu, J., Wei, Y., Lin, J. and Lin, S., Study on starchg-acrylamide/mineral powder superabsorbent composite. Polymer, 44, 6513 (2003).

Zhang, J. P., Wang, Q. and Wang, A. Q., Synthesis and characterization of chitosan-g-poly(acrylic acid)/attapulgite superabsorbent composites. Carbohyd. Polym., 68: 367 (2007).

Zhou, H. Y., Zhang, Y. P., Zhang, W. F. and Chen, X. G., Biocompatibility and characteristics of injectable chitosan-based thermosensitive hydrogel for drug delivery. Carbohyd. Polym., 83, 1643 (2011). 